\title{
Real-World Use of Do-It-Yourself Artificial Pancreas Systems in Children and Adolescents With Type 1 Diabetes: Online Survey and Analysis of Self-Reported Clinical Outcomes
}

Katarina Braune $^{1^{*}}$, MD; Shane O'Donnell ${ }^{2 *}$, PhD; Bryan Cleal ${ }^{3}, \mathrm{PhD}$; Dana Lewis ${ }^{4}$, BA; Adrian Tappe ${ }^{5}$, BSc; Ingrid Willaing ${ }^{3}$, MPH; Bastian Hauck ${ }^{6}$, MA; Klemens Raile ${ }^{1}$, MD

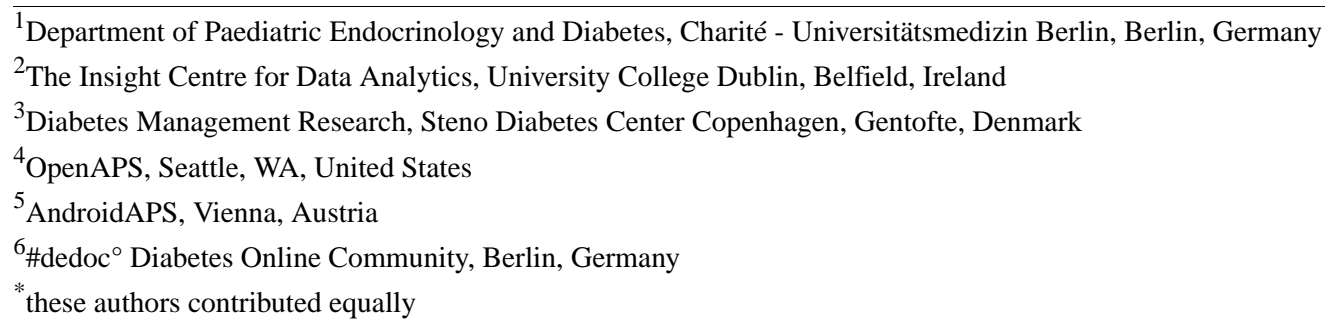

\section{Corresponding Author:}

Katarina Braune, MD

Department of Paediatric Endocrinology and Diabetes

Charité - Universitätsmedizin Berlin

Augustenburger Platz 1

Berlin, 13353

Germany

Phone: 4930450566615

Fax: 4930450566916

Email: katarina.braune@charite.de

\section{Abstract}

Background: Patient-driven initiatives have made uptake of Do-it-Yourself Artificial Pancreas Systems (DIYAPS) increasingly popular among people with diabetes of all ages. Observational studies have shown improvements in glycemic control and quality of life among adults with diabetes. However, there is a lack of research examining outcomes of children and adolescents with DIYAPS in everyday life and their social context.

Objective: This survey assesses the self-reported clinical outcomes of a pediatric population using DIYAPS in the real world. Methods: An online survey was distributed to caregivers to assess the hemoglobin $\mathrm{A}_{1 \mathrm{c}}$ levels and time in range (TIR) before and after DIYAPS initiation and problems during DIYAPS use.

Results: A total of 209 caregivers of children from 21 countries responded to the survey. Of the children, $47.4 \%$ were female, with a median age of 10 years, and $99.4 \%$ had type 1 diabetes, with a median duration of 4.3 years (SD 3.9). The median duration of DIYAPS use was 7.5 (SD 10.0) months. Clinical outcomes improved significantly, including the hemoglobin $\mathrm{A}_{1 \mathrm{c}}$ levels (from $6.91 \%$ [SD 0.88\%] to 6.27\% [SD 0.67]; $P<.001$ ) and TIR (from 64.2\% [SD 15.94] to 80.68\% [SD 9.26]; $P<.001$ ).

Conclusions: Improved glycemic outcomes were found across all pediatric age groups, including adolescents and very young children. These findings are in line with clinical trial results from commercially developed closed-loop systems.

(JMIR Mhealth Uhealth 2019;7(7):e14087) doi: 10.2196/14087

\section{KEYWORDS}

artificial pancreas; do it yourself; open source; mobile health; diabetes; type 1 diabetes; pediatric diabetes; closed loop; automated insulin delivery 


\section{Introduction}

Over 30 years ago, the Diabetes Control and Complications Trial showed benefits of intensive diabetes management in delaying the onset and reducing the severity of diabetes-related complications [1]. People diagnosed at a young age are particularly at risk for developing long-term complications and comorbidities during childhood and later throughout life. Owing to this, therapeutic guidelines recommend tight glycemic control, with a target hemoglobin $\mathrm{A}_{1 \mathrm{c}} \quad\left(\mathrm{HbA}_{1 \mathrm{c}}\right)$ level<7.0\% (53 $\mathrm{mmol} / \mathrm{mol}$ ) for all people with diabetes [2]. For children, adolescents, and young adults, guidelines even recommend the lowest achievable $\mathrm{HbA}_{1 \mathrm{c}}$ without undue exposure to severe hypoglycemia, balanced with quality of life and burden of care [3]. Today, despite significant advances in therapy and technological developments, only $17 \%$ of all children and adolescents with diabetes achieve an $\mathrm{HbA}_{1 \mathrm{c}}$ level<7.5\% (58 $\mathrm{mmol} / \mathrm{mol}$ ) [4].

Multiple clinical trials have shown that closed-loop insulin delivery systems (also known as automated insulin delivery systems or "artificial pancreas") designed for commercial use are safe and effective in reducing hyper- and hypoglycemia in people of all age groups with diabetes, including adolescents and children [5-9]. Closed-loop systems are characterized by automated insulin delivery in response to the user's glucose level. Although commercial systems are under development and some have recently become available in a limited number of countries, they are not universally available, accessible, or affordable. Behind the hashtag \#WeAreNotWaiting, a community of people with diabetes and their families have created new tools and systems, in addition to the existing, already approved medical devices, and shared them via open source platforms in order to help others with diabetes better utilize their devices and data. One of the most significant innovations to emerge through this movement is the Do-it-Yourself Artificial Pancreas System (DIYAPS). In DIYAPS, commercially available and approved medical devices such as insulin pumps and continuous glucose monitoring sensors are connected and remotely controlled by systems using open-source algorithms to automate insulin delivery. While these systems are cocreated by the DIYAPS community, each user has to build his/her own system and use it at his/her own risk. This includes children and adolescents whose caregivers build and maintain these systems on their behalf.

Initial observational studies have shown significant improvements in glycemic control, quality of life, and sleep quality in adult DIYAPS users [10-12]. A Czech pilot study was the first to report findings in a pediatric population and showed that AndroidAPS (an Android-based DIYAPS) was a safe and feasible alternative to a commercially available system, with predictive low glucose suspension during a winter sports camp [13]. There remains, however, a lack of research examining outcomes of children and adolescents with DIYAPS in everyday life and their social context. This survey assesses the self-reported clinical outcomes of this specific user group.

\section{Methods}

An online survey was distributed to caregivers using DIYAPS through the Facebook groups "Looped" (>11,500 members as of May 2019) and "AndroidAPS users" (>2800 members as of May 2019), other regional subgroups on Facebook, and Twitter. In this context, a caregiver was either a family member or another person who regularly looked after the child or adolescent with diabetes. Demographics and socioeconomic status of the study population were assessed. Participants were also asked for their child's last three $\mathrm{HbA}_{1 \mathrm{c}}$ measurements and mean time in range (TIR; sensor glucose level between $70 \mathrm{mg} / \mathrm{dL}$ or 4.0 $\mathrm{mmol} / \mathrm{L}$ and $180 \mathrm{mg} / \mathrm{dL}$ or $10.0 \mathrm{mmol} / \mathrm{L}$ ) before and after DIYAPS commencement. In an open-ended question, we asked respondents if they experienced difficulties in making the transition to DIYAPS.

The survey was designed by an interdisciplinary team of medical doctors, social scientists, public health researchers, and patient innovators. Participants were able to choose between two languages (English and German). Data were collected, managed, and analyzed using the secure REDCap electronic data capture tools hosted at Charité - Universitaetsmedizin Berlin [14]. Arithmetic mean, SD, and two-tailed heteroscedastic $t$ test were used to perform the statistical analysis. The survey was approved by the Charité ethics committee (EA2/140/18).

\section{Results}

Overall, 209 participants from 21 countries (74.3\% from Europe, $12.0 \%$ from North America, 6.9\% from Asia, and 6.9\% from Australia) responded to the survey (Table 1). Of the total, $47.4 \%$ children were female, with a median age of 10 years (range: 3-20 years), and $99.4 \%$ had type 1 diabetes. The median duration of diabetes was 4.3 (SD 3.9) years, and various types of DIYAPS (AndroidAPS, 48.0\%; OpenAPS, 28.4\%; Loop, 28.4\%; other, $3.4 \%$; and several systems over time, $7.5 \%$ ) were used. The group had used these systems for a median of 7.5 (SD 10.0) months. Analysis of caregivers' socioeconomic status indicated that the cohort was evenly distributed across a range of income groups. The responding caregivers' employment rate was $91.4 \%$, with $58.4 \%$ working full-time and $31.8 \%$ working part-time. Analysis of the education level showed that $65.2 \%$ had an academic or professional degree. 
Table 1. Demographic data of children and adolescents using Do-it-Yourself Artificial Pancreas Systems, who participated in this survey.

\begin{tabular}{lr}
\hline Demographic & $\mathrm{n}(\%)$ \\
\hline Child's gender & \\
Female & $83(47.4)$ \\
Male & $92(52.6)$
\end{tabular}

Child's age (years)

$\begin{array}{ll}3 & 6(3.4) \\ 4 & 11(6.3) \\ 5 & 14(8.0) \\ 6 & 14(8.0) \\ 7 & 12(6.9) \\ 8 & 12(6.9) \\ 9 & 15(8.6) \\ 10 & 20(11.4) \\ 11 & 9(5.1) \\ 12 & 19(10.9) \\ 13 & 11(6.3) \\ 14 & 10(5.7) \\ 15 & 12(6.9) \\ 16 & 2(1.1) \\ 17 & 2(1.1) \\ 18 & 2(1.1) \\ 20 & 4(2.3)\end{array}$

Child's type of diabetes

Type 1

174 (99.4)

Type 2

$0(0.0)$

Other/Unknown

$1(0.6)$

\section{Type of DIYAPS ${ }^{\mathrm{a}}$ used}

OpenAPS

AndroidAPS

Loop

Other/Unknown

Region (country of residence)

Europe

Austria

Bulgaria

Croatia

Czech Republic

Denmark

Finland

France

Germany

Greece

Ireland
43 (28.4)

$71(48.0)$

42 (28.4)

5 (3.4)

$130(74.3)$

$3(1.7)$

9 (5.1)

2 (1.1)

$12(6.9)$

2 (1.1)

8 (4.6)

$1(0.6)$

46 (26.3)

2 (1.1)

3 (1.7) 


\begin{tabular}{|c|c|}
\hline Demographic & $\mathrm{n}(\%)$ \\
\hline Luxembourg & $1(0.6)$ \\
\hline Poland & $2(1.1)$ \\
\hline Slovakia & $4(2.3)$ \\
\hline Spain & $3(1.7)$ \\
\hline Sweden & $8(4.6)$ \\
\hline Switzerland & $1(0.6)$ \\
\hline United Kingdom & $23(13.1)$ \\
\hline North America & $21(12.0)$ \\
\hline Canada & $5(2.9)$ \\
\hline United States & $16(9.1)$ \\
\hline Asia & $12(6.9)$ \\
\hline South Korea & $12(6.9)$ \\
\hline Australia/Western Pacific & $12(6.9)$ \\
\hline Australia & $12(6.9)$ \\
\hline \multicolumn{2}{|l|}{ Caregiver's occupational status } \\
\hline Full-time & $101(58.4)$ \\
\hline Part-time & $55(31.8)$ \\
\hline Unemployed & $10(5.8)$ \\
\hline Retired & $0(0.0)$ \\
\hline Student & $2(1.2)$ \\
\hline Other/Unknown & $5(2.9)$ \\
\hline \multicolumn{2}{|c|}{ Caregiver's household annual net income (US \$) } \\
\hline$<20,000$ & $19(12.0)$ \\
\hline $20,000-34,999$ & $12(7.6)$ \\
\hline $35,000-49,999$ & $19(12.0)$ \\
\hline $50,000-74,999$ & $33(20.9)$ \\
\hline $75,000-99,999$ & $24(15.2)$ \\
\hline$\geq 100,000$ & $40(25.9)$ \\
\hline
\end{tabular}

${ }^{a}$ DIYAPS: Do-it-Yourself Artificial Pancreas Systems.

On an average, the cohort already had a baseline glycemic control level below the target $\mathrm{HbA}_{1 \mathrm{c}}$ recommended by the International Society for Pediatric and Adolescent Diabetes [11]. Nevertheless, a significant $\mathrm{HbA}_{1 \mathrm{c}}$ improvement of -0.64 percentage points, from a mean $\mathrm{HbA}_{1 \mathrm{c}}$ of $6.91 \%$ (SD $0.88 \%$; or $52.0 \mathrm{mmol} / \mathrm{mol}$ ) to $6.27 \%$ (SD 0.67 ; or $45.0 \mathrm{mmol} / \mathrm{mol})$ after commencing DIYAPS was reported $(P<.001$; Figure 1$)$. The mean TIR increased from $64.2 \%$ (SD $15.94 \%$ ) to $80.68 \%$ (SD 9.26; $P<.001$; Figure 2). Participants also reported a continuous $\mathrm{HbA}_{1 \mathrm{c}}$ improvement over time, starting from a mean $\mathrm{HbA}_{1 \mathrm{c}}$ of $6.39 \%$ (SD $0.65 \%$; or $46.3 \mathrm{mmol} / \mathrm{mol}$ ) as their first result after commencement, which equals an improvement of -0.52 percentage points compared to the baseline level, gradually improving to a mean $\mathrm{HbA}_{1 \mathrm{c}}$ of $6.26 \%$ (SD $0.69 \%$; or 44.9 $\mathrm{mmol} / \mathrm{mol}$ ) as their second result and a mean $\mathrm{HbA}_{1 \mathrm{c}}$ of $6.06 \%$ (SD $0.66 \%$; or $42.7 \mathrm{mmol} / \mathrm{mol}$ ) as their third result, which equals an improvement of -0.85 percentage points. Users of all DIYAPS systems and all age groups showed similar results (Table 2).

Among the relatively few respondents who indicated difficulties with DIYAPS $(n=29)$, the primary challenge was sourcing the necessary devices and setting up the closed loop. In both cases, successful solutions were primarily found online, although for some, this was a time-consuming process. 
Figure 1. Mean last $\mathrm{HbA}_{1 \mathrm{c}}$ levels of children and adolescents before (black) and after (white) the initiation of Do-it-Yourself Artificial Pancreas Systems. $\mathrm{HbA}_{1 \mathrm{c}}$ : hemoglobin $\mathrm{A}_{1 \mathrm{c}}$.

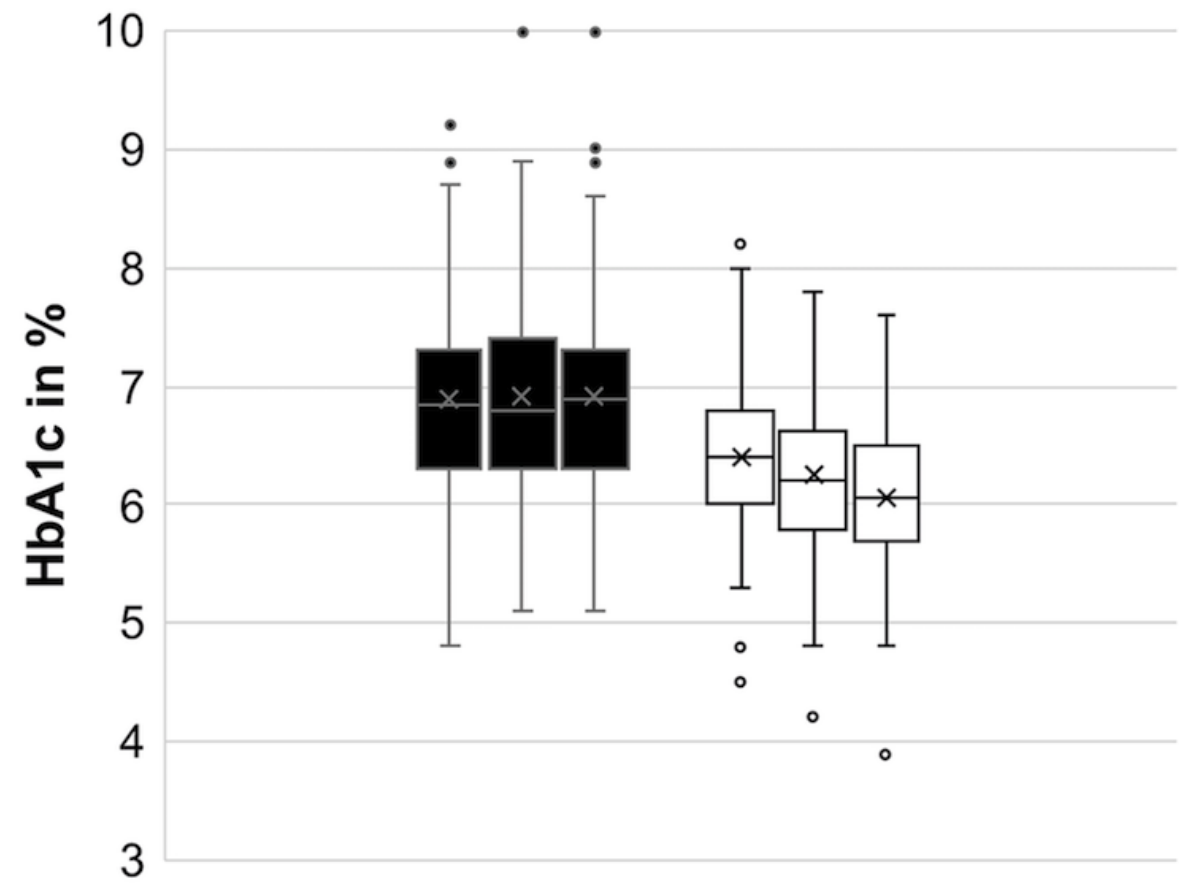

Figure 2. Mean time in range for sensor glucose levels of children and adolescents before (black) and after (white) the initiation of Do-it-Yourself Artificial Pancreas Systems.

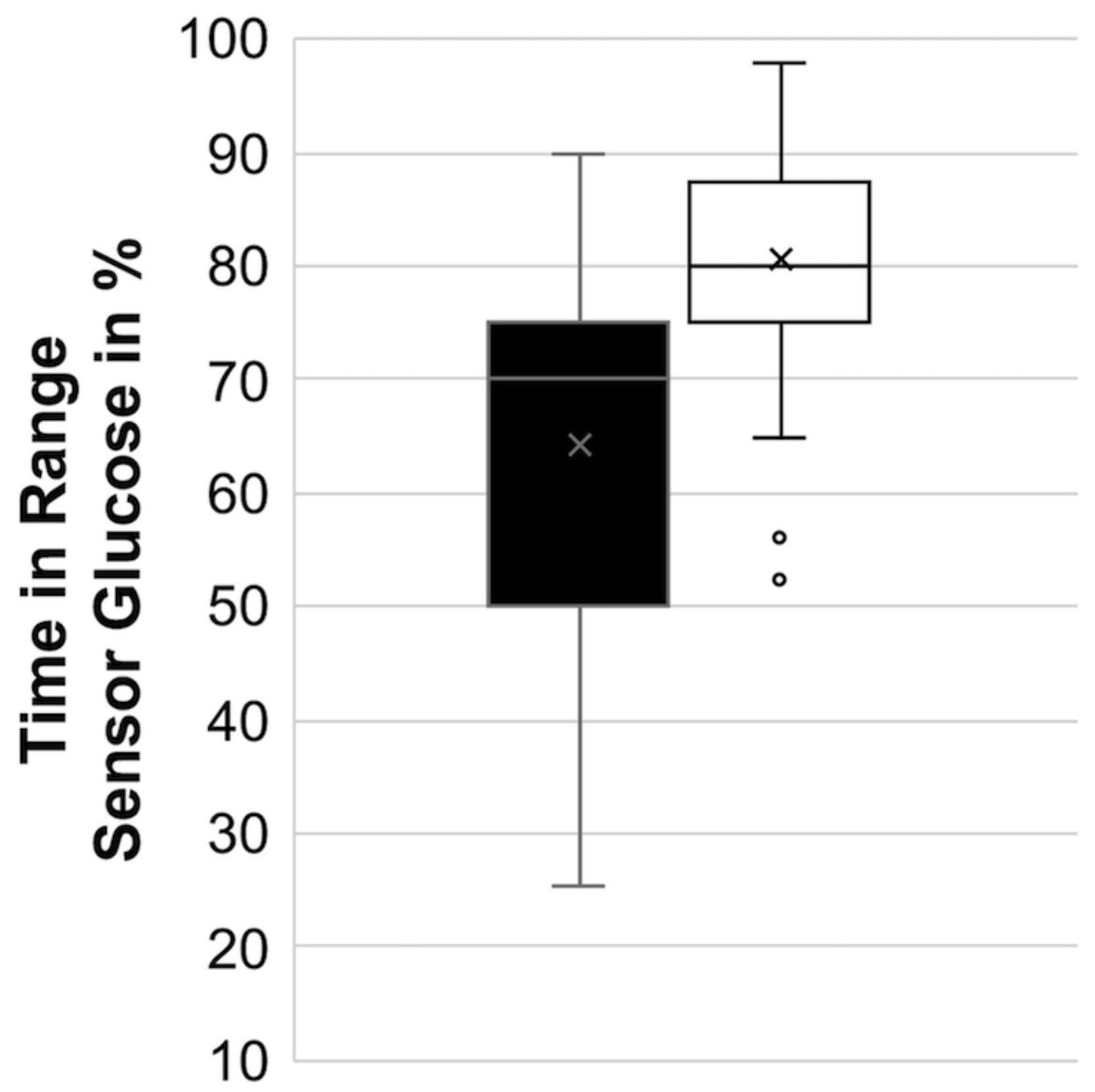


Table 2. Clinical outcomes in children and adolescents before and after initiation of Do-it-Yourself Artificial Pancreas Systems.

\begin{tabular}{ll}
\hline Outcomes and users & Mean (SD) \\
\hline
\end{tabular}

\section{All DIYAPS ${ }^{\text {a }}$ users}

$\mathbf{H b A}_{1 \mathbf{c}}{ }^{\mathbf{b}}$

Before

$6.91(0.88)$

After initiation

$6.27(0.67)$

Time in range

Before

After initiation

$80.68(9.26)$

OpenAPS users

$\mathrm{HbA}_{1 \mathrm{c}}$

Before

$7.10(0.75)$

After initiation

$6.36(0.72)$

Time in range

Before

67.1 (14.4)

After initiation

81.7 (7.7)

AndroidAPS users

$\mathrm{HbA}_{1 \mathrm{c}}$

Before

6.85 (0.79)

After initiation

$6.24(0.73)$

Time in range

Before

$63.8(15.0)$

After initiation

79.5 (7.9)

Loop users

$\mathrm{HbA}_{1 \mathrm{c}}$

Before

6.99 (1.00)

After initiation

$6.39(0.61)$

Time in range

Before

$64.2(15.4)$

After initiation

79.1 (8.4)

Children (3-9 years)

$\mathrm{HbA}_{1 \mathrm{c}}$

Before

$6.89(0.80)$

After initiation

Time in range

Before

After initiation

$79.2(8.4)$

Adolescents and young adults (10-20 years old)

$\mathrm{HbA}_{1 \mathrm{c}}$

Before

$6.93(0.95)$

After initiation

$6.23(0.75)$ 


\begin{tabular}{cc}
\hline Outcomes and users & Mean (SD) \\
\hline Time in range & $62.2(15.9)$ \\
Before & $80.1(9.3)$ \\
After initiation & \\
\hline
\end{tabular}

${ }^{a}$ DIYAPS: Do-it-Yourself Artificial Pancreas Systems.

${ }^{\mathrm{b}} \mathrm{HbA}_{1 \mathrm{c}}$ : hemoglobin $\mathrm{A}_{1 \mathrm{c}}$.

\section{Discussion}

This survey is currently the largest study of DIYAPS users on a global level and provides new evidence about real-world use of these systems in children and adolescents. Improvement of glycemic control was consistently reported across all pediatric age groups, including adolescents and very young children. Thus, the beneficial effects observed in adult users appear to apply to the pediatric population with no age limitations. These findings are in line with clinical trial results and improvements seen in commercially developed closed-loop systems [5-9].

The occupational and educational level of the responding caregivers was well above the population level; however, the household income levels varied. This finding suggests that DIYAPS may be financially accessible to a variety of socioeconomic groups. Further investigations on the role of all household caregivers' socioeconomic status and barriers to scaling up use of these systems would be of interest.

Although studies investigating DIYAPS consistently have demonstrated significant improvements in a variety of clinical and patient-reported outcomes, with no accompanying severe adverse events, various stakeholders continue to view the use of DIYAPS with skepticism. Ethical and legal questions have been raised, especially for the vulnerable group of children and adolescents. The off-label use of unregulated medical devices as well as the role of the caregiver taking the decision independently from doctors is the subject of intense debate [15]. Children are dependent on their caregivers' technological and medical knowledge and skills, both of which are prerequisites of understanding, building, and maintaining a DIYAPS. Moreover, a limited number of diabetes specialists are familiar with DIYAPS and their in-built safety mechanisms. Knowledge is also limited because research focusing on pediatric cohorts have tended to lag behind the adult population. Studies such as this one may therefore help alleviate concerns of health care providers as they are increasingly confronted with caregivers who have opted for DIYAPS for their child's diabetes management in their day-to-day clinical practice.

This study has several limitations. Outcomes were self-reported by caregivers. Until recently, self-reported data have not been commonly used in clinical research. However, a Norwegian study previously found that self-reported outcomes showed good concordance with data from patient registries reported by health care professionals [16]. Continuous glucose monitoring data were not directly captured in this survey. Therefore, time in hypoglycemia was not assessed. Time spans between $\mathrm{HbA}_{1 \mathrm{c}}$ measurements and TIR as well as DIYAPS versions, settings, and targets might differ individually. With a median DIYAPS experience of 7.5 months, some participants were unable to provide all three $\mathrm{HbA}_{1 \mathrm{c}}$ measurements. With education level and occupational status above the average population level and previous baseline glycemic outcomes below the target, the cohort or DIYAPS community may, in general, not be representative of all families having children with diabetes. To fully evaluate both the benefits and risks of DIYAPS, safety and efficacy trials for all age groups are needed.

The growing \#WeAreNotWaiting movement globally is indicative of a paradigm shift whereby traditional, top-down health care solutions are increasingly being complemented by bottom-up and patient-led initiatives. This survey, novel in both its sample size and international scope, provides new evidence that DIYAPS can offer substantial improvements in clinical outcomes for children and adolescents, even in a population that already has achieved glycemic outcomes below the target. However, more research is needed to examine the mechanisms by which these results are achieved; lived experiences of DIYAPS users; adverse events; and what can be learned from this movement in order to accelerate the diffusion of APS technology across the population.

\section{Acknowledgments}

We express our gratitude to the families of the DIYAPS community who supported and greatly contributed to this survey.

This survey is part of the EU-H2020 funded “OPEN"-project (Outcomes of Patients' Evidence with Novel, Do-it-yourself Artificial Pancreas Technology). OPEN is funded by the European Union Horizon 2020 Marie Skłodowska-Curie Actions Research and Innovation Staff Exchange (H2020-MSCA-RISE-2018) program.

\section{Authors' Contributions}

$\mathrm{KB}, \mathrm{DL}$, and KR performed the literature search. KB, SO, BC, AT, DL, BH, IW, and KR designed the survey. KB and KR collected the data. KB, SO, BC, AT, DL, BH, IW, and KR performed the data analysis and interpretation. KB, SO, KR, BC, IW, and DL wrote the article. All authors read and approved the article. 


\section{Conflicts of Interest}

KB reports grants from the Berlin Institute of Health (BIH) Clinician Scientist program; fees for medical consulting from Medtronic Diabetes as a member of the Advisory Board "Impact"; medical consulting fees from Roche Diabetes Care; and paid talks for Dexcom, Medtronic Diabetes, and Bertelsmann Stiftung outside the submitted work. AT reports personal fees from Dexcom, Roche Diabetes Care, IME-DC, and Ypsomed; nonfinancial support from Sooil; and personal fees from Gruber-Debong GmbH outside the submitted work. DL reports grants from Robert Wood Johnson Foundation and personal fees from Lilly, Diabeloop, Roche Diabetes Care, Novo Nordisk, and Tandem outside the submitted work. BH reports personal fees from Roche Pharma, Roche Diabetes Care, Novo Nordisk, LifeScan, Bayer AG, and Medtronic Diabetes outside the submitted work. KR is advisory board member of Lilly Diabetes Care and Abbott Diabetes Care outside the submitted work. The remaining authors declare no conflicts of interest.

\section{References}

1. Diabetes Control and Complications Trial Research Group, Nathan DM, Genuth S, Lachin J, Cleary P, Crofford O, et al. The effect of intensive treatment of diabetes on the development and progression of long-term complications in insulin-dependent diabetes mellitus. N Engl J Med 1993 Dec 30;329(14):977-986. [doi: 10.1056/NEJM199309303291401] [Medline: $\underline{8366922}$ ]

2. American Diabetes Association. Glycemic Targets. Diabetes Care 2018 Dec;41(Suppl 1):S55-S64. [doi: 10.2337/dc18-S006] [Medline: 29222377]

3. DiMeglio LA, Acerini CL, Codner E, Craig ME, Hofer SE, Pillay K, et al. ISPAD Clinical Practice Consensus Guidelines 2018: Glycemic control targets and glucose monitoring for children, adolescents, and young adults with diabetes. Pediatr Diabetes 2018 Dec;19 Suppl 27:105-114. [doi: 10.1111/pedi.12737] [Medline: 30058221]

4. Foster NC, Beck RW, Miller KM, Clements MA, Rickels MR, DiMeglio LA, et al. State of Type 1 Diabetes Management and Outcomes from the T1D Exchange in 2016-2018. Diabetes Technol Ther 2019 Feb;21(2):66-72. [doi: 10.1089/dia.2018.0384] [Medline: 30657336]

5. Tauschmann M, Allen JM, Wilinska ME, Thabit H, Acerini CL, Dunger DB, et al. Home Use of Day-and-Night Hybrid Closed-Loop Insulin Delivery in Suboptimally Controlled Adolescents With Type 1 Diabetes: A 3-Week, Free-Living, Randomized Crossover Trial. Diabetes Care 2016 Nov;39(11):2019-2025 [FREE Full text] [doi: 10.2337/dc16-1094] [Medline: 27612500]

6. Garg SK, Weinzimer SA, Tamborlane WV, Buckingham BA, Bode BW, Bailey TS, et al. Glucose Outcomes with the In-Home Use of a Hybrid Closed-Loop Insulin Delivery System in Adolescents and Adults with Type 1 Diabetes. Diabetes Technol Ther 2017 Dec;19(3):155-163 [FREE Full text] [doi: 10.1089/dia.2016.0421] [Medline: 28134564]

7. Tauschmann M, Thabit H, Bally L, Allen JM, Hartnell S, Wilinska ME, APCam11 Consortium. Closed-loop insulin delivery in suboptimally controlled type 1 diabetes: a multicentre, 12-week randomised trial. Lancet 2018 Dec 13;392(10155):1321-1329 [FREE Full text] [doi: 10.1016/S0140-6736(18)31947-0] [Medline: 30292578]

8. Tauschmann M, Allen JM, Nagl K, Fritsch M, Yong J, Metcalfe E, KidsAP Consortium. Home Use of Day and Night Hybrid Closed Loop Insulin Delivery in Very Young Children: A Multicenter 3-Week, Randomized Trial. Diabetes Care 2019 Jan 28. [doi: 10.2337/dc18-1881] [Medline: 30692242]

9. Forlenza GP, Pinhas-Hamiel O, Liljenquist DR, Shulman DI, Bailey TS, Bode BW, et al. Safety Evaluation of the MiniMed 670G System in Children 7-13 Years of Age with Type 1 Diabetes. Diabetes Technol Ther 2019 Jan;21(1):11-19 [FREE Full text] [doi: 10.1089/dia.2018.0264] [Medline: $\underline{30585770]}$

10. Lewis D, Leibrand S, \#OpenAPS Community. Real-World Use of Open Source Artificial Pancreas Systems. J Diabetes Sci Technol 2016 Dec;10(6):1411 [FREE Full text] [doi: 10.1177/1932296816665635] [Medline: 27510442]

11. Lewis DM, Swain RS, Donner TW. Improvements in A1C and Time-in-Range in DIY Closed-Loop (OpenAPS) Users. Diabetes 2018 May;67(Supplement 1):352-OR. [doi: 10.2337/db18-352-OR]

12. Lewis D. History and Perspective on DIY Closed Looping. J Diabetes Sci Technol 2018 Oct 22:1932296818808307. [doi: 10.1177/1932296818808307] [Medline: $\underline{30348013]}$

13. Petruzelkova L, Soupal J, Plasova V, Jiranova P, Neuman V, Plachy L, et al. Excellent Glycemic Control Maintained by Open-Source Hybrid Closed-Loop AndroidAPS During and After Sustained Physical Activity. Diabetes Technol Ther 2018 Dec;20(11):744-750. [doi: 10.1089/dia.2018.0214] [Medline: 30285476]

14. Harris PA, Taylor R, Thielke R, Payne J, Gonzalez N, Conde JG. Research electronic data capture (REDCap)--a metadata-driven methodology and workflow process for providing translational research informatics support. J Biomed Inform 2009 Apr;42(2):377-381 [FREE Full text] [doi: 10.1016/j.jbi.2008.08.010] [Medline: 18929686]

15. Barnard KD, Ziegler R, Klonoff DC, Braune K, Petersen B, Rendschmidt T, et al. Open Source Closed-Loop Insulin Delivery Systems: A Clash of Cultures or Merging of Diverse Approaches? J Diabetes Sci Technol 2018 Nov;12(6):1223-1226. [doi: 10.1177/1932296818792577] [Medline: 30079769]

16. Løvaas KF, Cooper JG, Sandberg S, Røraas T, Thue G. Feasibility of using self-reported patient data in a national diabetes register. BMC Health Serv Res 2015 Dec 15;15:553 [FREE Full text] [doi: 10.1186/s12913-015-1226-0] [Medline: 26666413] 


\section{Abbreviations}

DIYAPS: Do-it-Yourself Artificial Pancreas Systems

HbA $_{1 \mathbf{c}}$ : hemoglobin $\mathrm{A}_{1 \mathrm{c}}$

TIR: time in range

Edited by G Eysenbach; submitted 21.03.19; peer-reviewed by J Lee, S Lenz, AS Poncette, S Höll, U Thurm, K Panduro Madsen, L Heinemann, M Litchman; comments to author 08.05.19; revised version received 14.06.19; accepted 16.06.19; published 30.07.19

Please cite as:

Braune K, O'Donnell S, Cleal B, Lewis D, Tappe A, Willaing I, Hauck B, Raile K

Real-World Use of Do-It-Yourself Artificial Pancreas Systems in Children and Adolescents With Type 1 Diabetes: Online Survey and Analysis of Self-Reported Clinical Outcomes

JMIR Mhealth Uhealth 2019;7(7):e14087

URL: http://mhealth.jmir.org/2019/7/e14087/

doi: $\underline{10.2196 / 14087}$

PMID: $\underline{31364599}$

CKatarina Braune, Shane O'Donnell, Bryan Cleal, Dana Lewis, Adrian Tappe, Ingrid Willaing, Bastian Hauck, Klemens Raile. Originally published in JMIR Mhealth and Uhealth (http://mhealth.jmir.org), 30.07.2019. This is an open-access article distributed under the terms of the Creative Commons Attribution License (https://creativecommons.org/licenses/by/4.0/), which permits unrestricted use, distribution, and reproduction in any medium, provided the original work, first published in JMIR mhealth and uhealth, is properly cited. The complete bibliographic information, a link to the original publication on http://mhealth.jmir.org/, as well as this copyright and license information must be included. 